\title{
Measurements of Accompanying Air, Specific Surface Area and Micropore Volume of Some Flour Particles
}

\author{
Yoko SHIMIY** and Toshimasa Yano \\ Department of Agricultural Chemistry, The University of Tokyo, \\ Bunkyo-ku, Tokyo 113, Japan \\ Received May 6, 1986
}

\begin{abstract}
The volume of air accompanying flour particles was determined through the measurement of the apparent density and compared with the volume of micropores, smaller than $30 \mathrm{~nm}$ in diameter, of the flour particles, which was measured by the Cranston-Inkley method. Weak wheat flour had the largest amount of accompanying air, strong wheat flour an intermediate amount, and rice flour the least. Most of the air accompanying the wheat flours was held in pores larger than $30 \mathrm{~nm}$ in diameter, while most of the air accompanying the rice flour was held in pores smaller than $30 \mathrm{~nm}$ in diameter. From the viewpoint of the expansion of dough, the condition of the wheat flours was much better than that of the rice flour.
\end{abstract}

It is known empirically that flours used in baking have to hold a large amount of air. ${ }^{1)}$ The contributions of the held air in baking may be such as lowering of the density of the dough, supplying oxygen to the yeast, preparing bubble nuclei for homogeneous expansion, etc. Anyhow, the use of flours with a low amount of air does not allow good homogeneous expansion of the food materials. In this sense, sifting is not only an operation of classification on the basis of size but also an operation to increase the air content of flours. Even the aging of flours, which is necessary before flours can be used for making breads ${ }^{2}$ ) and cakes, ${ }^{3)}$ increases their air content (to be reported in the following paper). The air held in flours may be divided into two parts. One is the bulk air held between particles and the other is the air held inside the particles. The latter, the air held inside particles, which is referred to as the accompanying air hereafter, was measured as a characteristic parameter of flours, and compared among some samples of wheat and rice flours in this study. The specific surface area and the micropore volume of the sample flours were also measured for comparison

\section{MATERIALS AND METHODS}

Flours. Commercially available strong wheat flours, a weak wheat flour, a rice flour and starches were used. Table I shows the approximate chemical compositions of the flours. Starches were separated from strong wheat flour and rice flour by the toluene method ${ }^{4)}$ and used as flour samples.

Chemical analyses. The lipid content was measured by the ethyl ether extraction method. ${ }^{5)}$ The crude protein content was determined by the micro-Kjeldahl method; the nitrogen content times 5.70 for the wheat flours and times 5.95 for the rice flour. $\left.{ }^{6}\right)$ Dry weight of a sample was determined by drying it at $105^{\circ} \mathrm{C}$ for $5 \mathrm{hr}$.

The specific volume of air accompanying flour particles. This was calculated from the apparent densities of flour particles with and without accompanying air. ${ }^{7)}$ The apparent density of the flour particles with accompanying air was measured, with a picnometer using the following relation.

$$
\rho_{\mathrm{f}}=\left(W_{\mathrm{s}}-W_{0}\right) \cdot \rho_{\mathrm{w}} /\left\{\left(W_{\mathrm{w}}-W_{0}\right)-\left(W_{\mathrm{sw}}-W_{\mathrm{s}}\right)\right\}
$$

Since $5 \sim 10 \mathrm{~g}$ of the flour particles was suspended in $50 \mathrm{~cm}^{3}$ of distilled water in the picnometer, the air held between the flour particles was removed completely. The reciprocal of $\rho_{\mathrm{f}}$ is the apparent specific volume of the flour 
Table I. Approximate Compositions of Sample Flours

\begin{tabular}{lccc}
\hline \multicolumn{1}{c}{ Flour } & $\begin{array}{c}\text { Lipids } \\
{[\mathrm{kg} / \mathrm{kg}-\mathrm{D} . \mathrm{M} .]}\end{array}$ & $\begin{array}{c}\text { Proteins } \\
{[\mathrm{kg} / \mathrm{kg}-\mathrm{D} . \mathrm{M} .]}\end{array}$ & $\begin{array}{c}\text { Carbo-hydrates } \\
\text { and minerals } \\
{[\mathrm{kg} / \mathrm{kg}-\mathrm{D} . \mathrm{M} .]}\end{array}$ \\
\hline Strong wheat flour A & 0.0095 & 0.1355 & 0.8550 \\
Strong wheat flour B & 0.0105 & 0.1229 & 0.8666 \\
Strong wheat flour B* & 0.0097 & 0.1208 & 0.8695 \\
Weak wheat flour & 0.0108 & 0.1032 & 0.8860 \\
Rice flour & 0.0042 & 0.0744 & 0.9214 \\
Rice flour* & 0.0101 & 0.0719 & 0.9180 \\
\hline
\end{tabular}

Particle size, $74 \sim 125 \mu \mathrm{m}$; particle size for *, $<46 \mu \mathrm{m}$; D.M., dry matter.

particles with accompanying air.

$$
V_{\mathrm{f}}=1 / \rho_{\mathrm{f}}
$$

Then a flour-water suspension within the picnometer was degassed under vacuum for about 5 days in the presence of $400 \mu \mathrm{g} / \mathrm{cm}^{3}$ chloramphenicol until no bubble formation was observed, and the intrinsic density and specific volume of the flour particles were obtained as follows.

$$
\begin{gathered}
\rho_{\mathrm{f}}{ }^{*}=\left(W_{\mathrm{s}}-W_{0}\right) \cdot \rho_{\mathrm{w}} /\left\{\left(W_{\mathrm{w}}-W_{0}\right)-\left(W_{\mathrm{sw}}^{*}-W_{\mathrm{s}}\right)\right\} \\
V_{\mathrm{f}} *=1 / \rho_{\mathrm{f}} *
\end{gathered}
$$

The swelling of particles in water did not change the total volume of the suspension significantly. Therefore, the value of $\rho_{\mathrm{f}}$ * was not affected significantly by swelling, as the right hand side of Eq. (3) suggests. From Eqs. (2) and (4), the specific volume of air accompanying the flour particles is

$$
V_{\mathrm{a}}=V_{\mathrm{f}}-V_{\mathrm{f}}^{*}
$$

The time course of the change in the value of $V_{\mathrm{a}}$ after a sample flour had been suspended in water was measured by correcting the value of $W_{\mathrm{sw}}$ in Eq. (1), adding distilled water to the picnometer when the volume of the suspension decreased.

Nitrogen adsorption isotherm. The fraction of the flour particles between 74 and $125 \mu \mathrm{m}$ in diameter was used in this experiment. The sample was dehydrated first over $\mathrm{P}_{2} \mathrm{O}_{5}$ for 5 days, and then degassed with a vacuum pump for about 2 days at room temperature until the rate of the vapor pressure increase under the vacuum reached below $0.03 \mathrm{mmHg} / \mathrm{min}$. The nitrogen adsorption isotherm at liquid nitrogen temperature $\left(-195^{\circ} \mathrm{C}\right)$ was determined by using $5 \mathrm{~g}$ of a flour sample with an Accusorb 2100-01 (Shimadzu Seisakujo). Helium was used for the dead space determination.

Specific surface area. ${ }^{8)}$ The specific surface area of the flour particles was calculated from the nitrogen adsorption isotherm using Brunauer, Emmett and Teller's infinite layer adsorption equation ${ }^{9)}$ in the range of $0.1<$ $P / P_{0}<0.25$.

$$
\frac{P}{v\left(P_{0}-P\right)}=\frac{1}{v_{\mathrm{m}} \cdot C}+\frac{C-1}{v_{\mathrm{m}} \cdot C} \cdot \frac{P}{P_{0}}
$$

From a plot of $P / v\left(P_{0}-P\right)$ vs. $P / P_{0}$ which yielded a straight line, the value of $v_{\mathrm{m}}$ was determined. The specific surface area of the flour particles was then calculated as follows.

$$
S=A\left(v_{\mathrm{m}} / 2.24 \times 10^{-2}\right) \times 6.02 \times 10^{23}\left[\mathrm{~m}^{2} / \mathrm{kg}\right]
$$

By taking the value of $A$ as $0.162 \mathrm{~nm}^{2}$, Eq. (7) becomes

$$
S=4.35 \times 10^{6} \times v_{\mathrm{m}}\left[\mathrm{m}^{2} / \mathrm{kg}\right]
$$

Specific pore volume distribution. ${ }^{8)}$ The specific pore volume distribution was computed from the nitrogen adsorption isotherm. The relationship between the volume of pores and the volumn of the adsorbed nitrogen was given by Cranston and Inkley ${ }^{10)}$ as follows by combining Brunauer, Emmett and Teller's multilayer adsorption theory and the capillary condensation theories.

$$
\begin{aligned}
V_{12} & =R_{12}\left(v_{12}-k_{12} \sum_{r=r_{2}+(1 / 2) \Delta r}^{r_{\max }} \frac{r-t_{12}}{2 r^{2}} \cdot V_{r} \Delta r\right) \\
R_{12} & =\frac{r_{2}-r_{1}}{\int_{r_{1}}^{r_{2}}\left[\left(r-t_{1}\right)^{2} / r^{2}\right] d r} \\
k_{12} & =4\left(t_{2}-t_{1}\right), \quad t_{12}=1 / 2\left(t_{1}+t_{2}\right)
\end{aligned}
$$

The values of $R_{12}, k_{12}$ and $\left(r-t_{12}\right) / 2 r^{2}$ for pores less than $30 \mathrm{~nm}$ in diameter were experimentally obtained as constants by Cranston and Inkley. ${ }^{\text {io) }}$ The specific pore volume was obtained as the sum of the specific volumes of pores less than $30 \mathrm{~nm}$ in diameter. A Canon BX-30, one of the accessories for the Accusorb 2100-01, was used for the computation.

\section{RESULTS}

1) Amount of air accompanying flour particles

Figure 1 shows the specific volume of air accompanying flour particles suspended in water. Since the volume of the accompanying air decreased with time, the time courses of its 


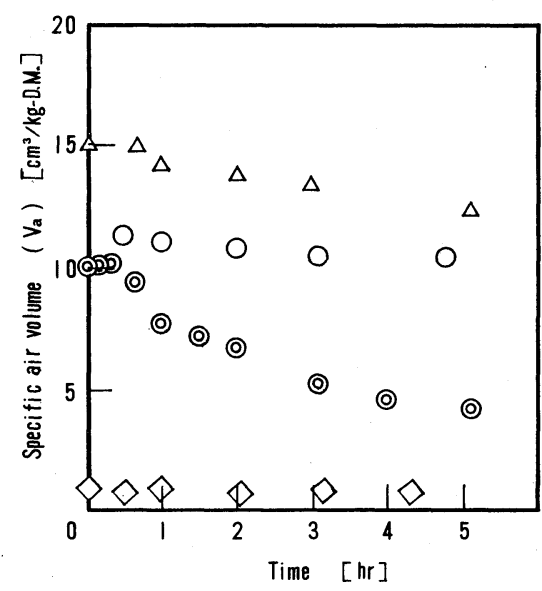

FIG. 1. Specific Volume of Air Accompanying Wheat and Rice Flours Dispersed in Water.

O, strong wheat flour $\mathrm{A}, d_{\mathrm{p}}=74 \sim 125 \mu \mathrm{m}$; (O), strong wheat flour $\mathrm{B}, d_{\mathrm{p}}=74 \sim 125 \mu \mathrm{m} ; \triangle$, weak wheat flour, $d_{\mathrm{p}}=74 \sim 125 \mu \mathrm{m} ; \diamond$, rice flour, $d_{\mathrm{p}}=74 \sim 125 \mu \mathrm{m}$.

change are also shown in Fig. 1. The weak wheat flour, which is usually used to make soft porous foods such as sponge cakes, cookies etc. without fermentation by yeasts, had the largest amount of accompanying air, the strong wheat flours, which are used to make elastic porous foods such as bread with fermentation by yeasts, also had a relatively large amount of accompanying air, but the rice flour had lesseven less than $1 / 10$-accompanying air than in the cases of the wheat flours. As to the accompanying air per single particle, each particle of the wheat flours carries an air bubble of $24 \sim 30 \mu \mathrm{m}$ in equivalent diameter, while each particle of the rice flour carries an air bubble of only about $11 \mu \mathrm{m}$ in equivalent diameter. The specific volume of the accompanying air decreased very slowly, so it took about 5 days for the accompanying air to become dissolved completely.

Figure 2 compares the specific volumes of air accompanying different particle size fractions. The smaller particles of wheat flour had the larger specific volume of accompanying air, although the difference between the rice flour particles was not significant.

Figure 3 shows the specific volumes of air accompanying the starch flours separated from the wheat and rice flours in comparison with

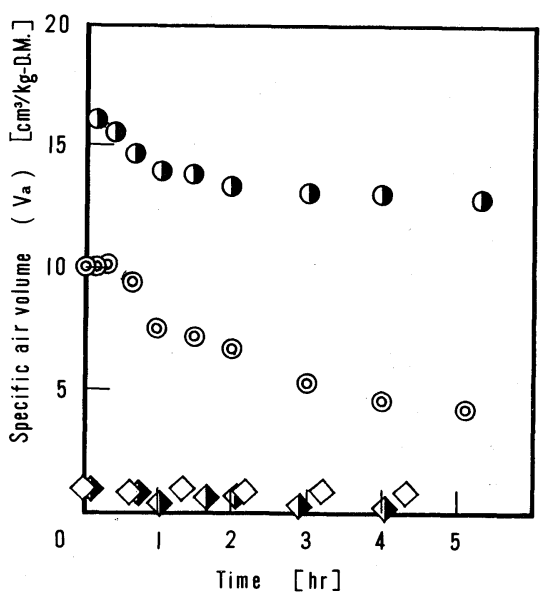

FIG. 2. Effect of Particle Size on the Specific Air Volume.

(O), strong wheat flour $\mathrm{B}, d_{\mathrm{p}}=74 \sim 125 \mu \mathrm{m}$; $\boldsymbol{D}$, strong wheat flour B, $d_{\mathrm{p}}<46 \mu \mathrm{m} ; \diamond$, rice flour, $d_{\mathrm{p}}=74 \sim 125 \mu \mathrm{m}$; $\diamond$, rice flour, $d_{\mathrm{p}}<46 \mu \mathrm{m}$.

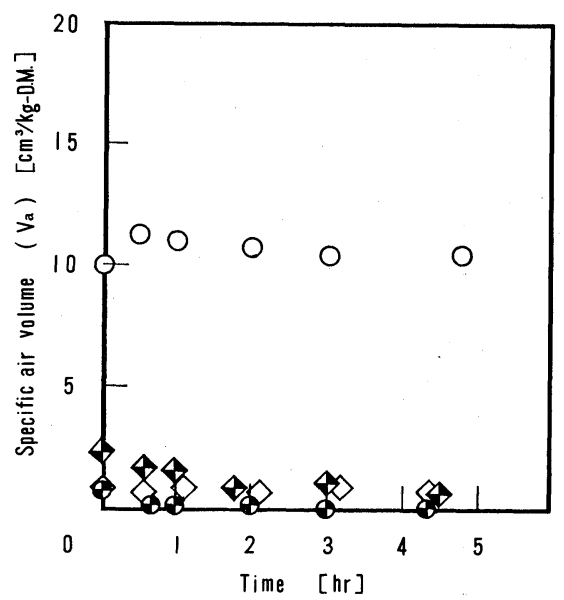

FIG. 3. Comparison of Specific Air Volume between Starch Separated from Flours and the Original Flours.

$\bigcirc$, strong wheat flour $\mathrm{A}, d_{\mathrm{p}}=74 \sim 125 \mu \mathrm{m} ; \boldsymbol{\Theta}$, starch separated from strong wheat flour $\mathrm{A} ; \diamond$, rice flour, $d_{\mathrm{p}}=74 \sim 125 \mu \mathrm{m} ; \diamond$, starch separated from rice flour.

those of the original flours. As Fig. 3 shows, the starch flours had low amounts of accompanying air.

\section{2) Specific surface area and micropore volume of flours}

Figure 4 shows the nitrogen adsorption isotherms of the strong wheat flour, weak wheat flour and rice flour at $-195^{\circ} \mathrm{C}$. The weak 


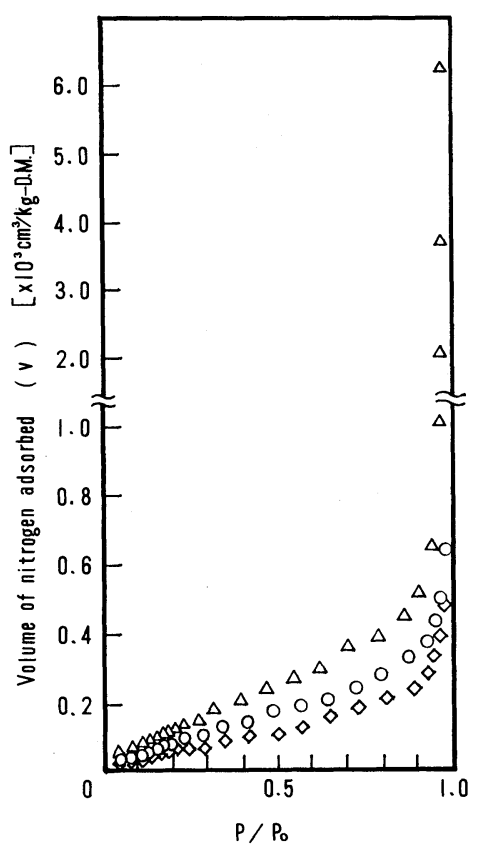

Fig. 4. Nitrogen Adsorption Isotherms of Various Flours at $-195^{\circ} \mathrm{C}$.

Symbols: as in Fig. 1.

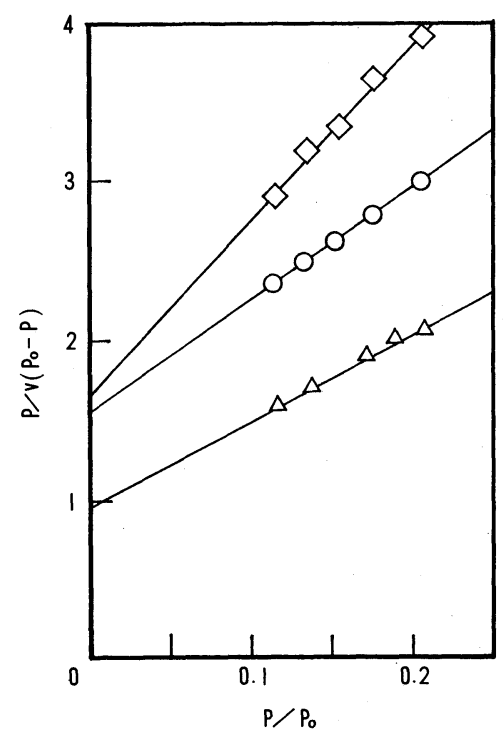

FIG. 5. Plot of $P / v\left(P_{0}-P\right) v s . P / \mathrm{P}_{0}$. Symbols: as in Fig. 1.

wheat flour had the largest nitrogen adsorption capacity, the strong wheat flour an intermediate capacity and the rice flour the lowest, corresponding to the order of the

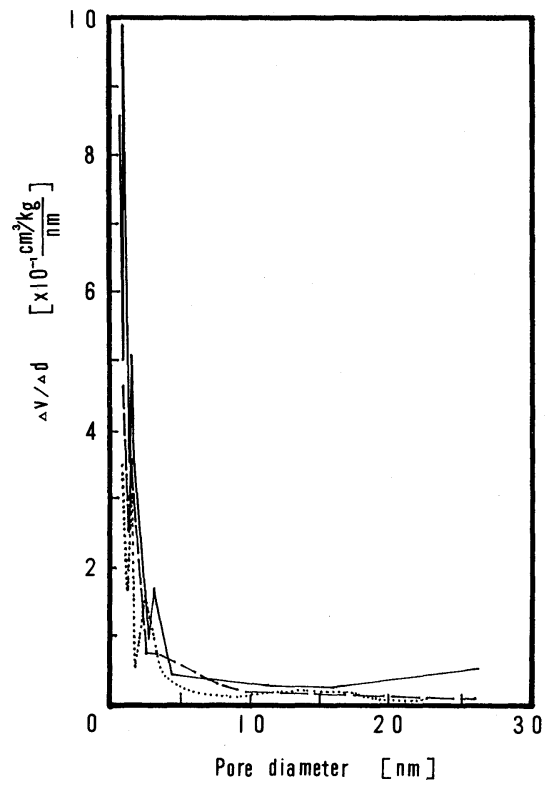

FIG. 6. Micropore Volume Distribution of Various Flours.

--, strong wheat flour A, $d_{\mathrm{p}}=74 \sim 125 \mu \mathrm{m}$; - , weak wheat flour, $d_{\mathrm{p}}=74 \sim 125 \mu \mathrm{m} ;----$, rice flour, $d_{\mathrm{p}}=74 \sim 125 \mu \mathrm{m}$. $\Delta v / \Delta d$ : pore volume differentiated with pore diameter.

specific volume of air accompanying the flours. Using the data in Fig. 4, plots of Eq. (6), $P / v\left(P_{0}-P\right)$ vs. $P / P_{0}$, are shown in Fig. 5. In the range between 0.1 and 0.25 of $P / P_{0}$, straight lines were obtained, from the slopes and the intersections of the ordinate of which the respective values of $v_{\mathrm{m}}$ were obtained. The specific surface areas were then calculated from Eq. (8), as shown in Table II. The value varied from 344 to $682 \mathrm{~m}^{2} / \mathrm{kg}$, corresponding. to the order for the specific air volume; rice flour, strong wheat flour and weak wheat flour.

The distribution as to the specific volume of micropores with diameters less than $30 \mathrm{~nm}$ is shown in Fig. 6. There was a sharp peak in the micropore distribution around the diameter of 2 to $3 \mathrm{~nm}$. The integrated volume of the specific pore volume from zero to $30 \mathrm{~nm}$ in diameter is shown in Table II for the sample flours. Comparison of the accompanying air with the micropore volume in Table II shows that most of the air accompanying the wheat 
Table II. Accompanying Air, Specific Surface Area and Micropore Volume of Flours

\begin{tabular}{lccc}
\hline Flour & $\begin{array}{c}\text { Accompanying } \\
\text { air } \\
{\left[\mathrm{cm}^{3} / \mathrm{kg}-\mathrm{D} . \mathrm{M} .\right]}\end{array}$ & $\begin{array}{c}\text { Specific surface } \\
\text { area } \\
{\left[\mathrm{m}^{2} / \mathrm{kg}-\mathrm{D} . \mathrm{M} .\right]}\end{array}$ & $\begin{array}{c}\text { Micropore } \\
\text { volume } \\
{\left[\mathrm{cm}^{3} / \mathrm{kg}-\mathrm{D} . \mathrm{M} .\right]}\end{array}$ \\
\hline Weak wheat flour & 15.0 & 682 & 1.93 \\
Strong wheat flour A & 11.3 & 503 & 0.96 \\
Strong wheat flour B & 10.0 & - & 0.74 \\
Rice flour & 0.9 & 344 & 0.74 \\
\hline
\end{tabular}

Particle size, $74 \sim 125 \mu \mathrm{m}$; micropores, $<30 \mathrm{~nm}$.

flours is held in pores larger than $30 \mathrm{~nm}$ in diameter, while the air accompanying the rice flour is held mostly in smaller micropores less than $30 \mathrm{~nm}$ in diameter. This is important because, when flours are mixed with water, the fine air bubbles accompanying the rice flour particles will have an inside pressure higher than that of the larger air bubbles accompanying the wheat flour particles, which should make the expansion of rice flour dough more difficult than that of wheat flour dough.

\section{DISCUSSION}

Although the significance of the "air content" of flours might have been recognized in food industries, quantitative measurement of the amount of air accompanying flour particles has been little reported. The results of this study, especially the data in Table II, provide quite interesting information on the characters of flours. Wheat flours with relatively large amounts of accompanying air held in large pores inside particles have a much better condition than that of rice flour from the viewpoint of expansion in food processing. The wheat flours provide a lot of bubble nuclei for easy homogeneous expansion of dough when baked, while the air held inside the rice flour particles in smaller micropores in lesser amounts may not be effective as nuclei for expansion. The amount of air accompanying rice flour particles can be changed by certain treatments of the flour. The details of the treatments and their effects on the expansion property will be reported elsewhere.
Acknowledgments. The authors wish to thank Nisshin Seifun Co., Ltd. for providing the sample flours, and Japan Tobacco Inc. for helping them with the measurements of physical properties.

\section{NOMENCLATURE}

$A$ : cross-sectional area of a nitrogen molecule $\left[\mathrm{m}^{2}\right]$

$C$ : $\quad$ constant related to the heat of adsorption [-]

$d$ : diameter of micropores [m]

$d_{\mathrm{p}}$ : diameter of flour particles [m]

$P: \quad$ vapor pressure of nitrogen at a time of measurement [mmHg]

$P_{0}$ : $\quad$ saturated vapor pressure of nitrogen at a given temperature $[\mathrm{mmHg}]$

$r_{1}, r_{2}$ : radii of pores filled by nitrogen through capillary condensation at pressures $P_{1}$ and $P_{2}$, respectively [m]

$r_{\max }: \quad$ radius of the largest pore $[\mathrm{m}]$

$S: \quad$ specific surface area $\left[\mathrm{m}^{2} / \mathrm{kg}-\mathrm{D} . \mathrm{M}\right.$.]

$t_{1}, t_{2}$ : thicknesses of the adsorbed nitrogen layers at pressures $P_{1}$ and $P_{2}$, respectively [m]

$v$ : volume of nitrogen adsorbed at pressure $P$ [m³ $/ \mathrm{kg}-\mathrm{D} . \mathrm{M}$.]

$v_{\mathrm{m}}$ : volume of nitrogen required to form a monolayer on the surface of porous particles [ $\mathrm{m}^{3} / \mathrm{kg}$-D.M.]

$v_{12}$ : increment of adsorbed nitrogen according to a change of pressure from $P_{1}$ to $P_{2}\left[\mathrm{~m}^{3} / \mathrm{kg}-\mathrm{D} . \mathrm{M}\right.$.]

$V_{12}$ : $\quad$ specific volume of pores with radii between $r_{1}$ and $r_{2}\left[\mathrm{~m}^{3} / \mathrm{kg}\right.$-D.M.]

$V_{\mathrm{a}}$ : $\quad$ specific volume of air accompanying flour particles $\left[\mathrm{m}^{3} / \mathrm{kg}-\mathrm{D} . \mathrm{M}\right.$.]

$V_{\mathrm{f}}$ : apparent specific volume of flour particles with accompanying air [ $\mathrm{m}^{3} / \mathrm{kg}-\mathrm{D}$.M.]

$V_{\mathrm{f}}^{*} \quad$ specific volume of flour particles without accompanying air $\left[\mathrm{m}^{3} / \mathrm{kg}\right.$-D.M.]

$W_{\mathrm{o}}$ : weight of the picnometer $[\mathrm{kg}]$

$W_{\mathrm{s}}$ : total weight of a sample flour and the picnometer [kg]

$W_{\mathrm{w}}$ : total weight of the picnometer filled with water $[\mathrm{kg}]$

$W_{\text {sw }}$ : total weight of a sample flour with accompanying 
air and the picnometer filled with water [kg]

$W_{\mathrm{sw}}^{*}$ : total weight of a degassed sample flour and the picnometer filled with water $[\mathrm{kg}]$

Greek letters

$\rho_{\mathrm{f}}$ : $\quad$ apparent density of flour particles with accompanying air $\left[\mathrm{kg} / \mathrm{m}^{3}\right]$

$\rho_{\mathrm{f}}^{*}$ : density of degassed flour particles $\left[\mathrm{kg} / \mathrm{m}^{3}\right]$

$\rho_{\mathrm{w}}: \quad$ density of water $\left[\mathrm{kg} / \mathrm{m}^{3}\right]$

\section{REFERENCES}

1) For example, Y. Sakurai et al., "Sogoshokuryokogyo," Koseisha Koseikaku, Tokyo, 1975, p. 60.

2) Nippon Mugirui-kenkyukai, "Komugiko," Uni-Art Co., Ltd., Tokyo, 1976, p. 526.

3) A. C. Johnson and R. C. Hoseney, Cereal Chem., 57, 92 (1980).
4) M. Nakamura et al., "Denpunkagaku Handbook," ed. by J. Nikuni, Asakura-shoten, Tokyo, 1977, p. 167.

5) Department of Agricultural Chemistry, The University of Tokyo, "Jikken Nogeikagaku," Asakura-shoten, Tokyo, 1978, p. 321.

6) T. Yamanishi, "Shokuhingaku-jikken," Sangyotosho Co., Ltd., Tokyo, 1969, p. 41.

7) Huntaikogaku-kenkyukai, "Ryudo Sokutei Gijutsu," Nikkankogyo-shinbunsha, 1975, pp. 28 30.

8) T. Keii, "Kyuchaku," Kyoritsu Publishing Co., Tokyo, 1979, pp. 95 131.

9) S. Brunauer, P. H. Emmett and E. Teller, J. Am. Chem. Soc., 60, 309 (1938).

10) R. W. Cranston and F. A. Inkley, Adv. Catal., 9, 143 (1957). 